\title{
ПОДБОР ПЕРСОНАЛА: ОПЫТ ЗАРУБЕЖНЫХ СТРАН
}

\author{
Шахгираев И.У., \\ Товсултанова П.И., \\ Ахматханов X.X.
}

Чеченский государственный университет, г. Грозный, Россия

Проведен анализ практики отбора персонала на муниципальную службу, характеристика и оценка применяемого инструментария в процессе кадровых процедур, направленных на выявление компетенций кандидата на конкурсе на замещение должностей мунищипальной службь.

Ключевые слова: США, Европа, отбор персонала, муниципальная служба, регулирование рынка труда, развитые страны, Россия.

Уплачивая налоги в казну государства, граждане рассчитывают на быструю и компетентную работу органов власти. Так как большая часть этих налогов за рубежом перенаправляется впоследствии на местный уровень, к нему граждане также формируют определенные требования. Чтобы им соответствовать и действовать эффективно, местные органы власти должны быть обеспечены квалифицированными кадрами. Отбор и последующий прием на работу муниципальных служащих является проблемой органов местного самоуправления по всему миру. В некоторых случаях решение подобных вопросов становится прерогативой органов государственной власти.

В целях определения наиболее распространенных методов отбора персонала на муниципальной службе в зарубежных странах и определения возможностей их экстраполяции в российскую практику авторами был проведен теоретический анализ сложившейся практики в США, Канаде и Великобритании. Теория, материалы и методы исследования Методическую базу работы составляют такие методы исследования, как анализ, обобщение, сравнение (общенаучные методы). Эмпирической базой исследования послужили официальные сайты органов местного самоуправления и гсоударственной власти зарубежных стран, исследования о практике отбора персонала местного самоуправления в зарубежных странах как отечественных, так и иностранных авторов. Результаты исследования и их обсуждение Закон (акт) о местном самоуправлении Великобритании 1989 года зафиксировал принципы меритократии не только в оценке работы государственных и муниципальных служащих, но и при их приеме на службу. Это значит, что кандидатов при найме подвергают строгой оценке и отбору на ее основе. При организации отбора кадров в органы местного самоуправления необходимо предварительно планировать каждый из этапов отбора, а также его подготовку. На данный момент существует множество методов отбора кадров, однако 
кадровые службы различных ведомств используют весьма ограниченное количество проверенных методов.

Обычно процедура отбора персонала проходит в несколько этапов:

1. Подготовка документов для проведения конкурса (содержит всю информацию, документы, регламентирующие процесс, описание должности, членов конкурсной комиссии, примерные вопросы интервью и др.).

2. Формирование конкурсной комиссии (включая подготовку членов по всем вопросам конкурса, выбор председателя отборочной комиссии).

3. Установка критериев отбора (знания, навыки, установки кандидатов на должность).

4. Объявление конкурса (используются различные пути: рекламные объявления, сайты, профессиональные отраслевые издания, привлечение консультантов, ярмарки и выставки вакансий).

5. Предварительный отбор (члены комиссии рассматривают резюме, происходит отбор по формальным критериям, а также ранжирование кандидатов в соответствии с критериями).

6. Проведение конкурса (включает в себя тестирование, интервью).

7. Проверка рекомендаций кандидатов (от предыдущих работодателей).

8. Предложение должности наиболее успешному кандидату. Количество и содержание данных этапов может варьироваться в зависимости от страны и ее законодательной базы, однако основное содержание конкурса остается неизменным [3].

Эксперты из Великобритании отмечают, что уже на этапе подготовки к проведению конкурса можно значительно облегчить работу комиссии и организаторов в дальнейшем. При правильной формулировке объявления об открытии вакансии уже начинается отбор кандидатов, так как различные люди обращают свое внимание на определенные аспекты места работы, должности и требований.

Таким образом, явка необходимых кандидатов может быть обеспечена уже при подготовке первых 3-4 этапов конкурса. В контексте данного исследования представляют интерес этапы проведения непосредственно конкурса на замещение должности, а также проверка рекомендаций (этапы 5 и 6). Наиболее достоверными при отборе кадров являются методы моделирования работы («job simulation»), которые включают защиту презентации, выполнение заданий, тестов с использованием компьютера и так далее). Подобные методы позволяют предположить, как работник будет выполнять должностные обязанности в будущем. Также эффективным считается метод систематического анализа биографических данных кандидатов («Biodata»). Предоставленные кандидатом или собранные сотрудниками данные систематизируются и на их основе производятся выводы: может ли кандидат занимать данную должность [1].

Результаты интервью, а также предоставленные рекомендации считаются методами низкой достоверности. Опираясь только на интервью или анализ истории предыдущих мест работы, зачастую не всегда можно определить, 
какой из представленных кандидатов в большей степени подходит на должность. Таким образом, более эффективным можно считать подход, сочетающий в себе несколько различных методов отбора персонала, однако решение об их использовании каждый муниципалитет принимает самостоятельно. Те же эксперты отмечают, что органы местного самоуправления чаще используют отдельные методы в «чистом» виде, хотя более эффективными являются их комбинации. Органы государственного управления в различных странах, решая проблемы подбора кадров в местные органы власти, создают методические рекомендации по проведению конкурсов, в которых описывают основные шаги, требования, а также сложности организации отбора кандидатов. Так, Правительство Канады (совместно с Общественным Правительством), в рамках развития системы управления человеческими ресурсами, издало рекомендации по отбору персонала для муниципалитетов Северо-Западных территории. Данный регион характеризуется сложными условиями проживания (сходными с российскими регионами Крайнего Севера). Одной из главных проблем данного региона является недостаток компетентных управленческих кадров. Рекомендации Правительства не носят нормативный характер, но опираются на законы Канады и представляют собой краткое изложение основ легитимного проведения конкурса. Рассмотрим методы, применяемые конкурсными комиссиями при отборе кадров в местные органы власти Северо-Западных территорий Канады.

Стоит отметить, что в зарубежной практике редко встречается понятие «конкурсной процедуры». Чаще всего используется термин «interview», который включает не только привычное в России «интервью» - ответы на соответствующие вопросы, но также и решение кейсов, анализ документов и так далее. Таким образом, методы, применяемые в Северо-Западных территориях Канады при отборе кадров в местные органы власти, сводятся к вопросам конкурсной комиссии (в форме теста и собеседования), основанным на рабочих ситуациях. Однако существует множество нюансов в проведении интервью, которые также учитываются при подготовке и в процессе проведения конкурса. Считается, что лучшим основанием для формулирования вопросов является описание работы и должности, на которую претендует конкурсант.

Также используются его документы (резюме, рекомендации, анкеты и т.д.). Вопросы могут уточнять:

- заинтересованность кандидата в работе;

- квалификацию;

- знания, навыки и профессиональную пригодность кандидата [3].

Члены комиссии интерпретируют и дифференцируют вопросы исходя из ситуации, сложившейся во время каждого конкретного интервью. Обычно 60$70 \%$ вопросов подготовлены заранее, остальные формулируются в процессе интервью. Комиссии запрещено задавать вопросы дискриминационного характера по любому из возможных оснований. Также не используются методы 
стресс - интервью, так как считается, что кандидаты испытывают нервное напряжение в достаточной степени, и нет необходимости усиливать его. Более того, организаторы конкурса должны убедиться, что для кандидата приготовлена вода или кофе. Стоит отметить, что в методических рекомендациях особое внимание уделяется подготовке комиссии, состоящей из 3-4 экспертов и Председателя («Committee Members and Chair Person»). Члены комиссии должны быть ознакомлены с материалами конкурса (критериями, резюме), а также быть профессионально вежливыми в процессе интервью.

Председатель следит за тем, чтобы конкурс проходил по обозначенному заранее плану:

1. Вступление, приветствие.

2. Вопросы интервью.

3. Подведение итогов интервью.

4. Рассмотрение рекомендаций.

5. Проведение теста, основанного на рабочих обязанностях («job-related test») $[2]$.

Таким образом, каждый из кандидатов проходит все этапы отбора, кроме тех, кто был «отсеян» по формальным критериям при подаче заявки и резюме. После проведения всех запланированных интервью, члены комиссии ранжируют кандидатов в соответствии с критериями, после чего осуществляется переход к этапу приглашения наиболее успешного кандидата к заключению контракта. Рассмотрим иной пример, из практики муниципального управления США. Департамент по делам территорий (подразделение по местному самоуправлению) штата Колорадо также создал методические рекомендации («Техническое руководство») по отбору персонала для органов местной власти. Рекомендации также обращают внимание на необходимость выработки четких критериев отбора, а также на недопустимость расовой, возрастной, гендерной и иных видов дискриминации.

Применяются различные методы отбора кадров в органы местного самоуправления: моделирование рабочих ситуаций, анализ биографических данных, тестирования, собеседования в форме интервью. Каждый муниципалитет самостоятельно определяет форму конкурсных испытаний и их порядок, a также назначает членов комиссии. В соответствии с рассмотренными примерами практического применения различных методов отбора персонала, можно сделать вывод: при отборе на муниципальную службу в Российской Федерации и рассмотренных зарубежных странах используются одинаковые методы (наиболее популярным является собеседование). Гораздо реже применяются иные, нестандартные методы, а также их сочетания. По данным исследований, «интервью и тесты способностей являются менее затратными и одновременно менее эффективными» по отношению к иным методам. В связи с этим является целесообразным комбинирование этих методов и формирование комплексного подхода к решению кадровых проблем в целом, и отборе персонала - в частности. 
В зарубежной практике осуществления местного самоуправления значительную роль играет уровень государственного управления. Разрабатываются методические рекомендации, включающие научные обоснования желательности применения тех или иных методов. Однако так же, как и в России, локальные власти должны сами выбирать способы, методы и инструменты, с помощью которых на данной территории происходит отбор муниципальных служащих. Рассмотрев нормативно-правовые основы отбора персонала на муниципальную службу в России и за рубежом, можно сделать следующий вывод: сформированная практика отбора персонала на муниципальную службу сводится, в основном, к конкурсным процедурам с применением методов тестировании и собеседования (интервью). Использование кадрового резерва, направленное на стратегически более эффективное решение кадровых проблем, применяется редко и, чаще всего, на уровне формального существования резерва. Анализ текущей ситуации показал существование возможностей развития системы отбора кадров на муниципальную службу с учетом различных инструментов, применение которых демонстрирует практика местного самоуправления, как в России, так и за рубежом.

\section{Исследование выполнено при финансовой поддержке РФФИ в рамках научного проекта № 19-310-90035/19.}

\section{Список литературы}

1. Оболонский А.В. Кризис бюрократического государства: Реформы государственной службы: международный опыт и российские реалии. М.: Фонд «Либеральная миссия», 2011.

2. McDonough P., Worts D., Fox B. \& Dmitrienko K. Restructuring municipal government: Labor-management relations and worker mental health // Canadian Review of Sociology. 2008. 45(2). PP. 197-219. doi:10.1111/j.1755618X.2008.00010.x.

3. Ashton M., Kushner J. \& Siegel D. Personality traits of municipal politicians and staff // Canadian Public Administration. 2007. 50(2). PP. 273-289. doi:10.1111/j.1754-7121.2007.tb02013.x. 